\title{
Obstructive Sleep Apnea Risk Is Associated with Cognitive Impairment after Controlling for Mild Traumatic Brain Injury History: A Chronic Effects of Neurotrauma Consortium Study
}

\author{
Amanda Garcia, ${ }^{1,2}$ Tea Reljic, ${ }^{3}$ Terri K. Pogoda, ${ }^{4,5}$ Kimbra Kenney, ${ }^{6,7}$ Amma Agyemang, ${ }^{8}$ Maya Troyanskaya, ${ }^{9,10}$ \\ Heather G. Belanger, ${ }^{11,12}$ Elisabeth A. Wilde, ${ }^{9,13,14}$ William C. Walker, ${ }^{8}$ and Risa Nakase-Richardson ${ }^{1,2,15}$
}

\begin{abstract}
The contribution of sleep disturbance to persistent cognitive symptoms following a mild traumatic brain injury (mTBI) remains unclear. Obstructive sleep apnea (OSA) is very common, yet its relationship between risk factors for developing OSA and cognitive performance in those with history of mTBI has not been investigated. The current study examined OSA risk levels and its association with cognitive performance in 391 combat-exposed, post-911 veterans and service members (median age $=37$ years) enrolled in the Chronic Effects of Neurotrauma Consortium (CENC) prospective multi-center study. Participants included those with and without mTBI ( $n=326$ and 65 , respectively). When using clinical cut-offs, those with history of mTBI were more likely to be categorized as high risk for OSA (mTBI positive $=65 \%$ vs. $\mathrm{mTBI}$ negative $=51 \%$ ). After adjustment for TBI status and demographic variables, increased OSA risk was significantly associated with worse performance on measures of complex processing speed and executive functioning (Wechsler Adult Intelligence Scale Fourth Edition Coding, Trail Making Test, part B) and greater symptom burden (Neurobehavioral Symptom Inventory). Thus, OSA, a modifiable behavioral health factor, likely contributes to cognitive performance following mTBI. Accordingly, OSA serves as a potential point of intervention to improve clinical and cognitive outcomes after injury.
\end{abstract}

Keywords: chronic effects; cognition; mild traumatic brain injury, military; mTBI; neurotrauma; obstructive sleep apnea; OSA

\section{Introduction}

$\mathbf{T}$ RAUMATIC BRAIN INJURY (TBI) is a major public health concern of special interest to the Departments of Defense (DoD) and Veterans Affairs (VA). ${ }^{1}$ The most current surveys find that over 410,000 U.S. military service members (SMs) have experienced a TBI, with estimates of roughly $23 \%$ of those returning from Operation Iraqi Freedom/Operation Enduring Freedom/Operation New
Dawn (OIF/OEF/OND). ${ }^{2,3}$ The vast majority of those injuries are classified as mild by DOD-VA criteria $(82.8 \%){ }^{2}$

Sleep disorders are common among active duty SMs with history of TBI. ${ }^{4-8}$ Obstructive sleep apnea (OSA) is cited as the most frequently diagnosed sleep disorder among military cohorts and is commonly reported in veteran samples. ${ }^{9,10}$ Sleep apnea is a sleeprelated breathing disorder characterized by repeated cessation (i.e., apnea) or near cessation (i.e., hypopnea) of ventilation during sleep.

${ }^{1}$ Defense and Veterans Brain Injury Center, ${ }^{2}$ Mental Health and Behavioral Sciences and Defense and Veterans Brain Injury Center, James A. Haley VA Hospital, Tampa, Florida, USA.

${ }^{3}$ Morsani College of Medicine, ${ }^{12}$ Department of Psychology and Psychiatry and Behavioral Neurosciences, ${ }^{15}$ Department of Internal Medicine, Sleep and Pulmonary Division, University of South Florida, Tampa, Florida, USA.

${ }^{4}$ Center for Healthcare Organization and Implementation Research, VA Boston Healthcare System, Boston, Massachusetts, USA.

${ }^{5}$ Boston University School of Public Health, Boston, Massachusetts, USA.

${ }^{6}$ National Intrepid Center of Excellence, Walter Reed National Military Medical Center, Bethesda, Maryland, USA.

${ }^{7}$ Department of Neurology, Uniformed Services University, Bethesda, Maryland, USA.

${ }^{8}$ Department of Physical Medicine and Rehabilitation, Virginia Commonwealth University, Richmond, Virginia, USA.

${ }^{9}$ Department of Physical Medicine and Rehabilitation, Baylor College of Medicine, Houston, Texas, USA.

${ }^{10}$ Michael E. DeBakey VA Medical Center, Houston, Texas, USA.

${ }^{11}$ United States Special Operations Command, Tampa, Florida, USA.

${ }^{13}$ George E. Wahlen VA Salt Lake City Healthcare System, Salt Lake City, Utah, USA.

${ }^{14}$ Department of Neurology, TBI and Concussion Center, University of Utah, Salt Lake City, Utah, USA.

(c) Amanda Garcia et al., 2020; Published by Mary Ann Liebert, Inc. This Open Access article is distributed under the terms of the Creative Commons Attribution Noncommercial License (http://creativecommons.org/licenses/by-nc/4.0/) which permits any noncommercial use, distribution, and reproduction in any medium, provided the original author(s) and the source are credited. 
The most prominent subtype of sleep apnea is the obstructive type (OSA). OSA is diagnosed when there is repetitive collapse or obstruction of the airway that results in oxygen desaturation (hypoxemia) and/or disturbance of sleep (arousals $[<15 \mathrm{sec}]$ or awakenings [>15 sec]), resulting in sleep fragmentation and non-restorative sleep.

Despite the high rates of comorbidity, the higher incidence of sleep apnea after TBI is poorly understood. However, large population-based studies suggest that sleep apnea may increase risk for TBI. Studies conducted on large samples demonstrate that the ill effects of sleep apnea were detectable several years prior to clinical diagnosis and treatment, and they are associated with behaviors that increase the risk of TBI, including work injuries and motor-vehicle accidents. ${ }^{11,12}$ For example, Young and colleagues conducted a national survey with 913 non-clinic based, employed individuals and reported severe sleep apnea was associated with a 7-fold increased risk of multiple auto-accidents in the 5 years prior to diagnosis. ${ }^{12}$ One Canadian study attributed 810,000 collisions and 1400 fatalities to sleep apnea, for a total cost of $\$ 15.9$ billion. $^{13}$

The presence of sleep apnea may also complicate our understanding of secondary injury cascades and recovery after TBI. Animal and human studies have shown that sleep-wake cycle disturbances may alter neurotransmitters and receptor systems, neuronal activation, and related signaling molecules, as well as physical functioning, mood, cognition, and behavior. ${ }^{14-17}$ Zunzunegu and colleagues demonstrated the moderating effects of sleep on several endogenous brain repair mechanisms in an animal model of brain injury. ${ }^{18}$ The hypoxemia of untreated sleep apnea and frequent disruptions of sleep due to awakenings from apneic events may impede the restorative benefits of sleep. The benefits of continuous restorative sleep were highlighted by a recent study showing greater accumulation of beta-amyloid proteins and other neurotoxins associated with neurodegenerative disorders with insufficient sleep. ${ }^{19-22}$ One mechanism for this benefit may be deep-sleep associated cerebrospinal fluid (CSF) clearance of neurotoxins. Indeed, the sleeping brain exhibits waves of CSF flow on a macroscopic scale, which are in turn interlinked with neural and hemodynamic rhythms. ${ }^{23}$ These rhythms may represent a biomarker of glymphatic clearance of tau protein and other metabolic byproducts from the brain that are associated with neurodegeneration. ${ }^{24,25}$

Collectively, chronic nighttime hypoxemia and frequent awakenings due to cessation of breathing may serve as mechanisms to potentiate and worsen outcomes following TBI. ${ }^{26,27}$ Cognitive sequelae of OSA include impairments in memory, attention, executive dysfunction, and response time. ${ }^{28-31}$ Additionally, neuroimaging has revealed changes in gray matter morphometry, ${ }^{32}$ white matter integrity, ${ }^{33}$ resting state connectivity, ${ }^{34}$ perfusion, ${ }^{35}$ and cerebrovascular response ${ }^{34}$ associated with OSA. Successful treatment of OSA with positive airway pressure therapies has been associated with improvement in cognition and reversal of white matter lesions following prolonged treatment. ${ }^{36,37}$

Cognitive disorders are common following moderate-to-severe TBI. ${ }^{28,38}$ Cognitive complaints following mild TBI (mTBI) also are common, ${ }^{39,40}$ despite the resolution of cognitive performance difficulties within 3 months of injury in studies comparing mTBI groups to control groups. ${ }^{31-43}$ It may be that some individuals are more vulnerable to persistent cognitive impairment after mTBI that are masked in group comparisons. One potential vulnerability is OSA. However, research into the role of OSA in cognitive symptoms and/or cognitive performance after $\mathrm{mTBI}$ is underdeveloped. To date, one study has shown worse cognitive performance (e.g., poorer sustained attention, delayed recall) for those with OSA in a small sample $(n=35)$ with mixed TBI severity. ${ }^{44}$ Therefore, the purpose of this paper is to examine the incidence of OSA risk and association with cognitive outcomes in both mTBI and non-TBI control participants leveraging the DOD- and VA-funded Chronic Effects of Neurotrauma Consortium (CENC) multi-center study.

\section{Methods}

Participants were veterans and service members across four U.S. Veterans Affairs Medical Centers enrolled in the first data-release sample of the CENC longitudinal study between January 2015 and August 2016. CENC inclusion criteria included: 1) history of deployment as part of OEF/OIF/OND or related follow-on conflicts; 2) history of combat exposure of any level on the Deployment Risk and Resiliency Inventory Section $\mathrm{D}^{45}$; and 3) $\geq 18$ years of age. Exclusion criteria were: 1) any lifetime moderate or severe TBI or 2) history of a major neurologic disorder resulting in significant decrease in functional status or loss of independent living capacity (e.g., stroke, spinal cord injury) or severe psychiatric disorder (e.g., schizophrenia). All participants provided written informed consent to participate, and all sites received approval from and followed the ethical standards of their respective institutional review boards and other required regulatory bodies.

Of participants enrolled, additional inclusion criteria for these secondary analyses included completion of baseline enrollment data on formal cognitive testing, self-reported cognitive functioning, and sleep apnea risk measures, as well as credible symptom reporting and cognitive performance data. Thus, additional exclusion criteria included failure of one or more embedded and/or stand-alone measures suggestive of invalid neuropsychological or self-report data.

\section{Measures}

TBI history. A modified version of the Ohio State University TBI Identification screening instrument was employed to identify lifetime potential concussive events (PCEs). ${ }^{46} \mathrm{PCE}$ information was captured by asking participants to identify any time when their head or neck was injured or possibly injured. Mechanism of injury for each PCE was documented as blast related (e.g., improvised explosive device, landmine) or non-blast related (e.g., motor vehicle accident, fall). Each PCE was then interrogated by detailed structured interview, the Virginia Commonwealth University retrospective Concussion Diagnostic Interview (VCU rCDI), which contains an embedded algorithmic preliminary diagnosis based on the DoD/VA common definition of mTBI. ${ }^{47}$ As described in more detail elsewhere, further vetting of this algorithm against medical records and rCDI free-text content was performed at the site level, as well as centrally to determine a final diagnosis. ${ }^{47}$ For the purpose of this analysis, mTBI history was labeled dichotomously (yes/no) and continuously (i.e., number of mTBIs).

Obstructive sleep apnea risk. A modified version of the STOP-BANG questionnaire was utilized for this study to avoid redundancy with other measures and minimize participant burden. ${ }^{48}$ Specifically, items from the Pittsburg Sleep Quality Index ${ }^{49}$ questionnaire were used as proxies for the first two STOP items, "Snoring" and "Tired," and an item from the Behavioral Risk Factor Surveillance System ${ }^{50}$ questionnaire was used as a proxy for the last STOP item "Pressure" (Table 1) to reduce participant burden. For the BANG portion, actual measurements were used for "Body mass index" and "Neck" size instead of self-report. The other items, "age" and "gender," were captured from the demographics form, using selfidentified sex for "gender." Items are summed with higher scores conveying greater risk. ${ }^{48}$ High risk was classified as STOP-BANG $\geq 3$, consistent with published clinical guidelines. ${ }^{48}$ Considering the overrepresentation of males in the current sample, additional analyses also were conducted in which high risk was classified at STOP-BANG $\geq 4$.

Cognitive functioning. Measures examining cognitive domains most commonly impacted by OSA and mTBI were chosen for analyses from the larger neuropsychological battery. Brief descriptions of these measures are provided below with more thorough descriptions in Table $2 .^{48-60}$ Memory was dichotomized into verbal and 
Table 1. Comparison of StOP-BANG Questions and those Administered as Part of the CENC Project

Question

number

STOP-BANG question

CENC question

1 Do you SNORE loudly (louder than talking or loud During the past month, how often have you had trouble sleeping enough to be heard through closed doors)?

2 Do you often feel TIRED, fatigued, or sleepy during daytime?

3 Has anyone OBSERVED you stop breathing during your sleep?

$4 \quad$ Do you have or are you being treated for high blood PRESSURE? because you cough or snore loudly?

During the past month, how often have you had trouble staying awake while driving, eating meals, or engaging in social activities? Has anyone observed you stop breathing during your sleep?

Have you $\boldsymbol{E V E R}$ been told by a doctor, nurse, or other health professional that you have high blood pressure?

CENC, Chronic Effects of Neurotrauma Consortium.

Table 2. List and Description of Measures

\begin{tabular}{|c|c|c|}
\hline Domain & Measure & Description \\
\hline \multirow[t]{2}{*}{ Memory } & $\begin{array}{l}\text { California Verbal Learning } \\
\text { Test-II (CVLT-II) }\end{array}$ & $\begin{array}{l}\text { The CVLT-II asks examinees to learn and remember a list of } 16 \text { words. It has been } \\
\text { used to meaningfully differentiate between severities of TBI }{ }^{48} \text { and to demonstrate } \\
\text { different types of memory impairments in TBI. }{ }^{49} \text { CVLT-II Long Delay Free Recall } \\
\text { score was used for analyses. Scores range from } 0 \text { to } 16 \text {, and a lower score indicates a } \\
\text { deficit in verbal learning or memory. }\end{array}$ \\
\hline & $\begin{array}{l}\text { Brief Visual Memory Test- } \\
\text { Revised (BVMT-R) }\end{array}$ & $\begin{array}{l}\text { The BVMT-R exposes examinees to } 6 \text { figures across } 3 \text { learning trials and later asks } \\
\text { them to recall the figures from memory. The BVMT-R has been successfully used to } \\
\text { evaluate cognitive deficits in neurological populations including concussions }{ }^{50} \text { and } \\
\text { to predict recovery from mild TBI. }{ }^{51,52} \text { Delayed Recall scores were used for } \\
\text { analysis. Scores range from } 0 \text { to } 12 \text {, with lower score indicating poorer recall. }\end{array}$ \\
\hline \multirow[t]{3}{*}{$\begin{array}{l}\text { Executive } \\
\text { functioning }\end{array}$} & Trail Making Test B (TMT B) & $\begin{array}{l}\text { TMT B asks examinees to accurately switch between numbers and letters, in order, } \\
\text { while visually scanning a page. TMT B has been shown to accurately classify } \\
\text { cognitive deficit after mild TBI }{ }^{53} \text { and to predict decision-making capacity in among } \\
\text { patients with TBI. }{ }^{54} \text { Quicker completion time (reported in raw seconds) denotes } \\
\text { better cognitive inhibition. }\end{array}$ \\
\hline & $\begin{array}{l}\text { Digit Span Backwards subtest, } \\
\text { WAIS-IV }\end{array}$ & $\begin{array}{l}\text { Digit Span Backwards asks examinees to hold and manipulate a string of numbers in } \\
\text { working memory. There is strong support for the clinical utility of these and other } \\
\text { WAIS-IV subtests in individuals with mild TBI. }{ }^{55} \text { Total scores are reported, with } \\
\text { higher scores indicating better working memory. }\end{array}$ \\
\hline & Flanker test & $\begin{array}{l}\text { This test measures to identify relevant and inhibit irrelevant information. A modified } \\
\text { version of the original test, updated for the NIH toolbox was used with examinees. } \\
\text { The NIH Toolbox has been validated for use in TBI. }{ }^{56} \text { The computed score, ranging } \\
\text { for } 0-10 \text { was used for analyses, with lower scores indicative of worse cognitive } \\
\text { inhibition. }\end{array}$ \\
\hline \multirow[t]{2}{*}{$\begin{array}{l}\text { Processing } \\
\text { Speed }\end{array}$} & Trail Making Test A (TMT A) & $\begin{array}{l}\text { TMT A asks examinees to quickly scan and connect a series of numbered circles. TMT } \\
\text { has been shown to accurately classify cognitive deficit after mild } \text { TBI }^{53} \text { and to } \\
\text { predict decision-making capacity in among patients with TBI. }{ }^{54} \text { Quicker completion } \\
\text { time (reported in raw seconds) denotes faster simple processing speed. }\end{array}$ \\
\hline & Coding subtest, WAIS-IV & $\begin{array}{l}\text { The coding subtest of the WAIS-IV measures complex processing speed. Raw scores } \\
\text { are reported, with higher numbers indicating faster processing speed. }\end{array}$ \\
\hline Self-Report & $\begin{array}{l}\text { Neurobehavioral Symptom } \\
\text { Inventory (NSI) }\end{array}$ & $\begin{array}{l}\text { The NSI is broken down into } 4 \text { subscales, representing commonly reported symptoms } \\
\text { following concussion: cognitive, affective, vestibular, and somatic. The cognitive } \\
\text { subscale was used for analyses and scores range from } 0-4 \text {. Higher numbers } \\
\text { represent more symptoms endorsed. }\end{array}$ \\
\hline \multirow[t]{3}{*}{ Effort } & $\begin{array}{l}\text { Medical Symptom Validity } \\
\text { Test (MSVT) }\end{array}$ & $\begin{array}{l}\text { The MSVT is a short verbal memory test, utilizing a paired associated learning } \\
\text { paradigm. Scores were considered unreliable if accuracy was less than } 85 \% \text {. }\end{array}$ \\
\hline & WAIS-IV Reliable Digit Span & $\begin{array}{l}\text { Reliable Digit Span is a composite of longest digit span forward }+ \text { longest digit span } \\
\text { backward, wherein both trials were accurate. Scores were considered unreliable if } \\
\text { combined reliable digit span was less than } 7 \text {. }\end{array}$ \\
\hline & $\begin{array}{l}\text { Mild Brain Injury Atypical } \\
\text { Symptoms (mBIAS) }\end{array}$ & $\begin{array}{l}\text { The mBIAS is a subscale of the Neurobehavioral Symptom Inventory, which consists } \\
\text { of atypical or rarely endorsed post-concussive symptoms. Reporting on this measure } \\
\text { was considered unreliable if scores were } \geq 8 \text {. }\end{array}$ \\
\hline
\end{tabular}

TBI, traumatic brain injury; WAIS-IV, Wechsler Adult Intelligence Scale 4th Edition. 
visual domains. Verbal learning and memory were captured with the California Verbal Learning Test-II (CVLT-II). ${ }^{61}$ Visual learning and memory were captured with the Brief Visual Memory Test-Revised. ${ }^{62}$ Processing speed was measured using the Trail Making Test A (TMT A) ${ }^{63}$ for simple processing speed and the Coding subtest of the Wechsler Adult Intelligence Scale Fourth Edition (WAIS-IV) ${ }^{64}$ for complex processing speed. Executive functioning was broken down into set-shifting, working memory, and mental inhibition. The Trail Making Test, part B (TMT B), ${ }^{63}$ Digit Span Backwards subtest of the WAIS-IV, and Flanker Inhibitory Control Test of the National Institutes of Health Toolbox Cognition Battery ${ }^{65}$ were used to measure each ability respectively. Finally, the Neurobehavioral Symptom Inventory (NSI) ${ }^{60,66}$ cognitive subscale was used to query self-reported post-concussive cognitive symptoms. Examination of effort includes use of the Medical Symptom Validity Test, Reliable Digit Span Index from the Digit Span Subtest of the WAIS-IV, and the Mild Brain Injury Atypical Symptoms addition to the NSI.

\section{Statistical analysis}

All statistical analyses were conducted using IBM SPSS Statistics. ${ }^{67}$ Descriptive statistics (percentages, means, quartiles) for participant, injury, and sleep apnea risk characteristics were used to describe participants retained in the analyses and those excluded. Chi-squared tests, Kruskal-Wallis Tests, and independent sample t-tests were used for comparing those retained and excluded. Multi-variate linear regression was used to evaluate the effect of OSA risk (continuous STOP-BANG score) after adjustment for mTBI status (dichotomous variable) and demographic variables known to affect cognitive performance (i.e., age, gender, race, education) across all cognitive performance and selfreported cognitive problems measures. Univariable linear regression also was calculated to permit examination of unadjusted effects for each predictor. Effects were reported as beta scores with confidence intervals. All statistical tests were two-sided tests of significance with an exploratory alpha level of 0.05 .

\section{Results}

\section{Sample characteristics}

This dataset consisted of the first 492 participants completing baseline evaluations. Participants were retained in analyses with complete cognitive and sleep apnea risk data resulting in a sample of 470 participants. Cases with failure of one or more performance effort or symptom exaggeration validity measures were additionally excluded, resulting in a final analytic sample of 391 participants with complete and reliable data (Fig. 1). Table 3 summarizes the overall sample stratified by TBI status ( $n=326$ for mTBI positive). Retained participants were predominantly male (88\%) with a high school education $(61 \%)$ and a median age of 37 years (interquartile range [IQR], 22 to 69). The median number of mTBIs was 2. (IQR range, 1 to 3 ) for the overall sample, with non-blast TBI more commonly observed (Table 3). No differences on demographic variables (age, gender, education, race) were observed between those with and without mTBI. Similarly, excluded participants did not differ from those retained in the overall sample on the same demographic variables. However, excluded participants compared with the retained overall sample had a trend toward increased number of mTBIs $(p=0.055)$.

\section{Sleep apnea risk}

Tables 4 and 5 summarize the individual risk items, subscales, and total STOP-BANG scores. Participants with an mTBI history had more risk factors for OSA compared with TBI negative controls $(p=0.006)$. When using recommended clinical cut-off scores for high risk (STOP-BANG $\geq 3$ ), $65 \%$ of those with a history of mTBI were identified as high risk compared with controls at $51 \%$ $(p=0.035)$. When examining a more stringent cut-off to account for the high number of males in this sample (STOP-BANG $\geq 4$ ), $44 \%$ of those with a history of mTBI were identified as high risk compared with controls at $26 \%(p=0.008)$. When the measure was examined more specifically, those with history of mTBI demonstrated higher risk on the sleep risk factors (i.e., STOP portion of STOP-BANG) compared with controls $(p=0.009)$. This finding was primarily driven by a higher prevalence of hypertension (i.e., STOP-BANG Item 4$)$ in this population $(p=0.039)$. Those with history of mTBI also were more likely to have a thicker neck

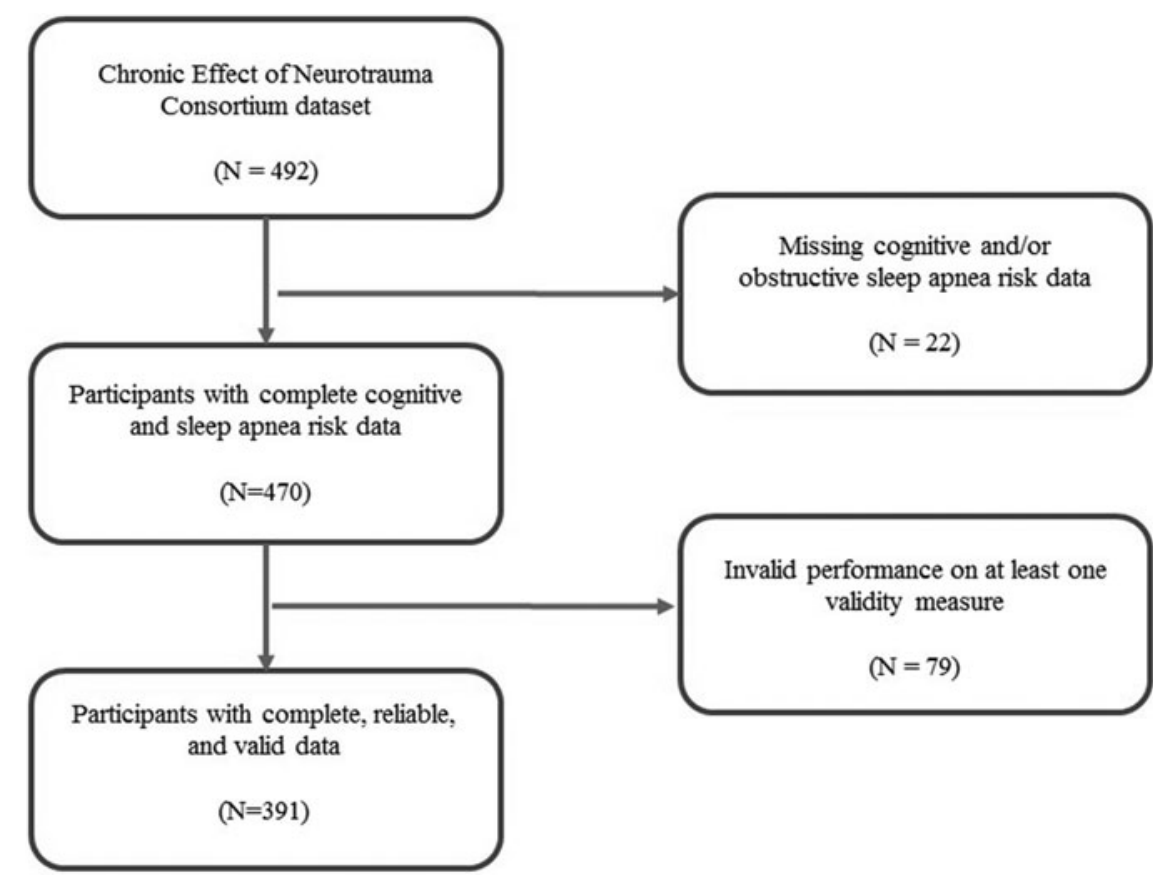

FIG. 1. Flow diagram of participants. 
Table 3. Characteristics of Participants and those Excluded

\begin{tabular}{|c|c|c|c|c|c|c|}
\hline & Full sample & TBI statı & & $\mathrm{p}$ value & Excluded cases & $\mathrm{p}$ value \\
\hline \multirow{3}{*}{$\begin{array}{l}\text { Demographics } \\
\text { Age }\end{array}$} & $n=391$ & $\begin{array}{l}\text { History of mild TBI } \\
n=326\end{array}$ & $\begin{array}{c}\text { Control } \\
n=65\end{array}$ & & $n=101$ & \\
\hline & 39.19 & 38.87 & 40.82 & 0.161 & 39.53 & 0.720 \\
\hline & $31 / 37 / 47$ & $31 / 36 / 47$ & $31.5 / 41 / 50$ & & $31 / 37 / 48$ & \\
\hline \multicolumn{4}{|l|}{ Gender } & 0.094 & & 0.138 \\
\hline Male & $344(88)$ & $291(89.3)$ & $53(81.5)$ & & $83(82.2)$ & \\
\hline Female & $47(12)$ & $35(10.7)$ & $12(18.5)$ & & $18(17.8)$ & \\
\hline \multicolumn{4}{|l|}{ Education } & 1.000 & & 0.553 \\
\hline Up to high school & $64(16.4)$ & $54(16.6)$ & $10(15.4)$ & & $19(18.8)$ & \\
\hline More than high school & $327(83.6)$ & $272(83.4)$ & $55(84.6)$ & & $82(81.2)$ & \\
\hline \multicolumn{4}{|l|}{ Race } & 0.417 & & 1.00 \\
\hline White & $192(49.1)$ & $163(50.9)$ & $29(44.6)$ & & $49(48.5)$ & \\
\hline Non-White & $196(50.1)$ & $160(49.1)$ & $36(55.4)$ & & $51(50.5)$ & \\
\hline \multicolumn{4}{|l|}{ H/o Learning Difficulties } & 0.572 & & 0.325 \\
\hline Yes & $24(6.1)$ & $19(5.8)$ & $5(7.7)$ & & $3(3.2)$ & \\
\hline No & $367(93.9)$ & $307(94.2)$ & $60(92.3)$ & & $92(96.8)$ & \\
\hline \multicolumn{7}{|l|}{ Injury characteristics } \\
\hline mTBI History & & $326(100)$ & & & $88(87.1)$ & 0.445 \\
\hline \multirow[t]{2}{*}{ mTBI Number } & & 2.46 & & & 2.32 & 0.055 \\
\hline & & $1 / 2 / 3$ & & & $1 / 2 / 3$ & \\
\hline \multirow[t]{2}{*}{ Total blast mTBI } & & 0.72 & & & 0.88 & 0.013 \\
\hline & & $0 / 0 / 1$ & & & $0 / 1 / 1$ & \\
\hline \multirow[t]{2}{*}{ Total non-blast mTBI } & & 1.74 & & & 1.44 & 0.928 \\
\hline & & $1 / 1 / 2$ & & & $0 / 1 / 2$ & \\
\hline
\end{tabular}

Continuous data presented as [mean, 25/50/75]. Categorical data presented as $[n(\%)]$.

TBI, traumatic brain injury; mTBI, mild traumatic brain injury.

Table 4. Description of OSA Risk by StOP-BANG Total Score, Subscales, and Individual Items

\begin{tabular}{|c|c|c|c|c|}
\hline \multirow[b]{3}{*}{ OSA risk } & \multirow[b]{2}{*}{ Overaxll sample } & \multicolumn{2}{|c|}{ TBI status } & \multirow[b]{3}{*}{$p$ value } \\
\hline & & TBI history & Control & \\
\hline & $\mathrm{n}=391$ & $\mathrm{n}=326$ & $\mathrm{n}=65$ & \\
\hline $\begin{array}{l}\text { STOP-BANG Item } 1 \text { (SNORE) } \\
\quad n(\%)\end{array}$ & $199(50.9)$ & $171(52.5)$ & $28(43.1)$ & 0.167 \\
\hline $\begin{array}{l}\text { STOP-BANG Item } 2 \text { (TIRED) } \\
n(\%)\end{array}$ & $141(36.1)$ & $121(37.1)$ & $20(30.8)$ & 0.330 \\
\hline $\begin{array}{l}\text { STOP-BANG Item } 3 \text { (OBSERVED Apneic Event) } \\
n(\%)\end{array}$ & $141(36.1)$ & $124(38.0)$ & $17(26.2)$ & 0.068 \\
\hline $\begin{array}{l}\text { STOP-BANG Item } 4 \text { (Blood PRESSURE) } \\
n(\%)\end{array}$ & $140(35.8)$ & $124(38.0)$ & $16(24.6)$ & 0.039 \\
\hline $\begin{array}{l}\text { STOP-BANG Item } 5 \text { (BMI) } \\
n(\%)\end{array}$ & $59(15.1)$ & $53(16.3)$ & $6(9.2)$ & 0.148 \\
\hline $\begin{array}{l}\text { STOP-BANG Item } 6 \text { (AGE) } \\
n(\%)\end{array}$ & $62(15.9)$ & $47(14.4)$ & $15(23.1)$ & 0.081 \\
\hline $\begin{array}{l}\text { STOP-BANG Item } 7 \text { (NECK) } \\
n(\%)\end{array}$ & $147(26.2)$ & $130(39.9)$ & $17(26.2)$ & 0.037 \\
\hline $\begin{array}{l}\text { STOP-BANG Item } 8 \text { (GENDER) } \\
n(\%)\end{array}$ & $344(88.0)$ & $291(89.3)$ & $53(81.5)$ & 0.080 \\
\hline $\begin{array}{l}\text { Total STOP score } \\
\text { Mean (SD) } \\
\text { Min/25/50/75/Max }\end{array}$ & $\begin{array}{c}1.588(1.184) \\
0 / 1 / 1 / 2 / 4\end{array}$ & $\begin{array}{l}1.656(1.179) \\
0 / 1 / 1.5 / 2.25 / 4\end{array}$ & $\begin{array}{l}1.246(1.160) \\
0 / 0 / 1 / 2 / 4\end{array}$ & 0.009 \\
\hline $\begin{array}{l}\text { Total BANG score } \\
\text { Mean (SD) } \\
\text { Min/25/50/75/Max }\end{array}$ & $\begin{array}{l}1.565(0.914) \\
0 / 1 / 1 / 2 / 4\end{array}$ & $\begin{array}{l}1.598(0.909) \\
0 / 1 / 1 / 2 / 4\end{array}$ & $\begin{array}{c}1.400(0.932) \\
0 / 1 / 1 / 2 / 4\end{array}$ & 0.086 \\
\hline STOP-BANG total Score & $\begin{array}{l}3.15 \\
2 / 3 / 4\end{array}$ & $\begin{array}{l}3.25 \\
2 / 3 / 4\end{array}$ & $\begin{array}{l}2.65 \\
1 / 3 / 4\end{array}$ & 0.006 \\
\hline OSA high risk $\geq 3$ & $245(62.7)$ & $212(65.0)$ & $33(50.8)$ & 0.035 \\
\hline High risk $\geq 4$ & $161(41.2)$ & $144(44.2)$ & $17(26.2)$ & 0.008 \\
\hline
\end{tabular}

Continuous data presented as [Mean, 25/50/75]. Categorical data presented as [raw number, percentage].

The $p$ value was determined by $\chi^{2}$ test for dichotomous variables and independent sample t-test (normally distributed data) or Kruskal-Wallis Test (non-normally distributed data) for continuous variables.

OSA, obstructive sleep apnea; TBI, traumatic brain injury; BMI, body mass index; SD, standard deviation. 
Table 5. Univariate and Multi-Variate Models of Memory Performance

\begin{tabular}{|c|c|c|c|c|c|}
\hline \multirow[b]{2}{*}{ Outcome variable } & \multirow[b]{2}{*}{ Predictor } & \multicolumn{2}{|l|}{ Univariate model } & \multicolumn{2}{|c|}{ Multi-variate model } \\
\hline & & Estimate $(95 \%$ CI) & $\mathrm{p}$ value & Estimate $(95 \%$ CI) & $\mathrm{p}$ value \\
\hline \multirow[t]{6}{*}{ CVLT-II } & Age & $-0.110(-0.142$ to -0.077$)$ & $<0.001$ & $-0.106(-.143$ to -.070$)$ & $<0.001$ \\
\hline & Gender & $-0.667(-1.739$ to 0.450$)$ & 0.222 & $-0.945(-2.05$ to 0.16$)$ & 0.092 \\
\hline & Race & $1.099(0.412$ to 1.787$)$ & 0.002 & $1.103(0.45$ to 1.75$)$ & 0.001 \\
\hline & Education & $-0.609(-1.543$ to 0.324$)$ & 0.200 & $0.015(-0.89$ to 0.92$)$ & 0.975 \\
\hline & TBI & $0.844(-0.081$ to 1.770$)$ & 0.074 & $0.680(-0.20$ to 1.56$)$ & 0.131 \\
\hline & STOP-BANG Score & $-0.350(-0.554$ to -0.145$)$ & 0.001 & $-0.073(-0.30$ to 0.15$)$ & 0.527 \\
\hline \multirow{6}{*}{ BVMT-R } & Age & $-0.082(-0.106$ to -0.059$)$ & $<0.001$ & -0.083 ( -0.11 to -0.06$)$ & $<0.001$ \\
\hline & Gender & $0.075(-0.707$ to 0.858$)$ & 0.850 & 0.084 ( -0.73 to 0.89$)$ & 0.838 \\
\hline & Race & $0.498(-0.013$ to 1.008$)$ & 0.056 & $0.515(0.03$ to 1.00$)$ & 0.037 \\
\hline & Education & $-0.206(-0.893$ to 0.482$)$ & 0.556 & $0.368(-0.31$ to 1.40$)$ & 0.285 \\
\hline & TBI & $-0.372(-1.054$ to 0.311$)$ & 0.285 & $-0.517(-1.17$ to 0.14$)$ & 0.123 \\
\hline & STOP-BANG Score & $-0.264(-0.414$ to -0.115$)$ & 0.001 & $-0.083(-0.25$ to 0.08$)$ & 0.327 \\
\hline
\end{tabular}

Estimates are presented as beta values.

CI, confidence interval; CVLT, California Verbal Learning Test-II; BVMT-R, Brief Visual Memory Test-Revised.

circumference (STOP-BANG Item 7; $p=0.037$ ). Items reflecting observed apneic events, age, and gender trended towards significant difference between groups (with the mTBI group demonstrating higher risk on all items), but they remained under the threshold for statistical difference.

\section{Univariable analyses of outcomes}

Univariable logistic regression analyses were performed for known predictors of cognition (age, gender, race, and education), TBI history, and OSA risk. Results of regression analyses showing unadjusted (univariable) beta score are presented in Tables 6-8. As expected, age significantly predicted performance across all measures of memory, attention, processing speed, and executive functioning, with varying effects noted for race and education across tasks. Given the predominantly male sample, no effect was observed for gender. History of mTBI was associated with lower complex processing speed (WAIS-IV Coding, confidence interval $[\mathrm{CI}]=$ -8.170 to -0.649 ) and higher number of self-reported cognitive problems (NSI Cognitive, $\mathrm{CI}=0.365$ to 0.874 ). In contrast, OSA risk, as measured by the STOP-BANG score, significantly predicted worse performance on all cognitive performance tasks and higher number of self-reported cognitive problems $(p<0.05$; Tables $5-8)$.

\section{Multi-variable analyses of outcomes}

Multi-variable linear regression was performed with all demographic predictors, TBI status, and OSA risk in the model simultaneously. Results showing the adjusted effect of each predictor (i.e., adjusted effect after accounting for other predictors in the model) are presented in Tables 5-8. After adjustment for other variables in the model, age and race were most consistently associated with cognitive performance, with variability across tasks for gender and education. In the adjusted model, both TBI status and

Table 6. Univariate and Multi-Variate Models of Attention/Executive Functioning Performance

\begin{tabular}{|c|c|c|c|c|c|}
\hline \multirow[b]{2}{*}{ Outcome variable } & \multirow[b]{2}{*}{ Predictor } & \multicolumn{2}{|l|}{ Univariate model } & \multicolumn{2}{|c|}{ Multi-variate model } \\
\hline & & Estimate $(95 \% \mathrm{CI})$ & $p$ value & Estimate $(95 \%$ CI) & $p$ value \\
\hline \multirow[t]{6}{*}{ TMT B } & Age & $0.526(0.315$ to 0.737$)$ & $<0.001$ & $0.482(0.248$ to 0.715$)$ & $<0.001$ \\
\hline & Gender & $-0.158(-6.946$ to 6.647$)$ & 0.964 & $-2.538(-9.603$ to 4.527$)$ & 0.480 \\
\hline & Race & $-8.100(-12.480$ to -3.721$)$ & $<0.001$ & $-8.126(-9.603$ to 4.527$)$ & $<0.001$ \\
\hline & Education & $-0.137(-6.119$ to 5.845$)$ & 0.964 & $-3.783(-9.672$ to 2.106$)$ & 0.207 \\
\hline & TBI & $5.372(-0.549$ to 11.293$)$ & 0.075 & $6.037(0.299$ to 11.774$)$ & 0.039 \\
\hline & STOP-BANG Score & $2.721(1.429$ to 4.013$)$ & $<0.001$ & $1.664(0.206$ to 3.121$)$ & 0.025 \\
\hline WAIS-IV Digit Span & Age & $-0.042(-0.062$ to -0.022$)$ & $<0.001$ & $-0.043(-0.065$ to -0.020$)$ & $<0.001$ \\
\hline \multirow[t]{5}{*}{ Backwards } & Gender & $-0.193(-0.834$ to 0.449$)$ & 0.555 & $0.098(-0.577$ to 0.773$)$ & 0.775 \\
\hline & Race & $0.446(0.034$ to 0.858$)$ & 0.034 & $0.458(0.055$ to 0.861$)$ & 0.026 \\
\hline & Education & $0.141(-0.423$ to 0.705$)$ & 0.623 & $0.434(-0.129$ to 0.997$)$ & 0.130 \\
\hline & TBI & $-0.389(-0.948$ to 0.171$)$ & 0.173 & $-0.465(-1.014$ to 0.083$)$ & 0.096 \\
\hline & STOP-BANG Score & $-0.201(-0.324$ to -0.078$)$ & 0.001 & $-0.085(-0.224$ to 0.055$)$ & 0.233 \\
\hline \multirow[t]{6}{*}{ Flanker } & Age & $-0.041(-0.050$ to -0.031$)$ & $<0.001$ & $-0.036(-0.046$ to -0.025$)$ & $<0.001$ \\
\hline & Gender & $0.097(-0.216$ to 0.411$)$ & 0.542 & $0.126(-0.187$ to 0.440$)$ & 0.428 \\
\hline & Race & $0.092(-0.116$ to 0.300$)$ & 0.385 & $0.095(-0.095$ to 0.285$)$ & 0.328 \\
\hline & Education & $-0.477(-0.749$ to -0.205$)$ & 0.001 & $-0.234(-0.495$ to 0.028$)$ & 0.080 \\
\hline & TBI & $-0.067(-0.342$ to 0.207$)$ & 0.630 & $-0.110(-0.364$ to 0.144$)$ & 0.394 \\
\hline & STOP-BANG Score & $-0.126(-0.186$ to -0.066$)$ & $<0.001$ & $-0.059(-0.124$ to 0.006$)$ & 0.075 \\
\hline
\end{tabular}

Estimates are presented as beta values.

CI, confidence interval; TMT B, Trail Making Test B; TBI, traumatic brain injury; WAIS-IV, Weschler Adult Intelligence Scale 4th Edition. 
Table 7. Univariate and Multi-Variate Models of Processing Speed Performance

\begin{tabular}{|c|c|c|c|c|c|}
\hline \multirow[b]{2}{*}{ Outcome variable } & \multirow[b]{2}{*}{ Predictor } & \multicolumn{2}{|l|}{ Univariate model } & \multicolumn{2}{|l|}{ Multi-variate model } \\
\hline & & Estimate $(95 \%$ CI) & $p$ value & Estimate $(95 \%$ CI) & $p$ value \\
\hline \multirow[t]{6}{*}{ TMT A } & Age & 0.277 (0.181 to 0.372$)$ & $<0.001$ & $0.311(0.205$ to 0.418$)$ & $<0.001$ \\
\hline & Gender & $0.239(-2.866$ to 3.344$)$ & 0.880 & $0.241(-2.988$ to 3.470$)$ & 0.883 \\
\hline & Race & $-2.580(-4.591$ to -0.569$)$ & 0.012 & $-2.713(-4.642$ to -0.785$)$ & 0.006 \\
\hline & Education & $-1.891(-4.614$ to 0.831$)$ & 0.173 & $-3.986(-6.677$ to -1.294$)$ & 0.004 \\
\hline & TBI & 0.821 ( -1.890 to 3.532$)$ & 0.552 & $1.511(-1.111$ to 4.133$)$ & 0.258 \\
\hline & STOP-BANG Score & $0.763(0.165$ to 1.360$)$ & 0.012 & $0.033(-0.633$ to 0.699$)$ & 0.923 \\
\hline \multirow[t]{6}{*}{ WAIS-IV Coding } & Age & $-0.393(-0.526$ to -0.260$)$ & $<0.001$ & $-0.402(-0.542$ to -0.262$)$ & $<0.001$ \\
\hline & Gender & $-11.667(-15.884$ to -7.450$)$ & $<0.001$ & $-9.849(-14.138$ to -5.561$)$ & $<0.001$ \\
\hline & Race & $1.735(-1.097$ to 4.567$)$ & 0.229 & $2.049(-0.485$ to 4.584$)$ & 0.113 \\
\hline & Education & $3.913(0.123$ to 7.703$)$ & 0.043 & $5.556(2.021$ to 9.091$)$ & 0.002 \\
\hline & TBI & $-4.409(-8.170$ to -0.649$)$ & 0.022 & $-3.648(-7.092$ to -0.203$)$ & 0.038 \\
\hline & STOP-BANG Score & $-2.729(-3.524$ to -1.933$)$ & $<0.001$ & $-1.185(-2.061$ to -0.309$)$ & 0.008 \\
\hline
\end{tabular}

Estimates are presented as beta values.

CI, confidence interval; TMT A, Trail Making Test A; TBI, traumatic brain injury; WAIS-IV, Weschler Adult Intelligence Scale 4th Edition.

OSA risk were associated with worse performance on measures of complex processing speed (WAIS-IV Coding, $p<0.05$; Table 7) and executive functioning (TMT B, $p<0.05$; Table 6). They also were both associated with higher self-reported cognitive problems (NSI cognitive, $p<0.001$; Table 8 ). The results remained unchanged when history of learning difficulties was entered into multi-variable models (data not presented). In other words, OSA risk is uniquely associated with some aspects of cognitive performance (speed of performance and executive functioning-cognitive sequencing) and perception of cognitive problems after adjustment for mTBI status in this cohort.

\section{Discussion}

This study found a high rate of OSA risk in the CENC longitudinal study population using a proxy STOP-BANG questionnaire. This is consistent with studies demonstrating high rates of OSA in military and veteran samples. ${ }^{68}$ A greater number of OSA risk factors was observed for those with a history of mTBI compared with controls without mTBI. Examination of risk status using traditional risk cut-off scores $(\geq 3)$ revealed $65 \%$ of those with a history of mTBI were at high risk of OSA compared with $51 \%$ among controls. Using a more stringent cut-off $(\geq 4)$, participants with a mTBI history (44\%) continued to evidence a differential risk compared with controls (26\%). These findings are consistent with the other single military study demonstrating that OSA is an especially prevalent co-morbidity of mTBI. ${ }^{69}$
Cognitive dysfunction is commonly reported after mTBI, ${ }^{41-43}$ with attribution often made to non-modifiable factors (i.e., TBI status). This study examined the association of a modifiable target (OSA risk) on cognitive performance and self-reported cognitive problems. Significant effects were found for OSA risk across all univariable analyses of cognitive outcome. After adjustment for demographics and TBI status, OSA risk was significantly associated with worse performance on certain measures of complex processing speed and executive functioning/cognitive sequencing and speed of responding combined. Both tasks are challenging and involve higher order cognitive processes. In other words, task complexity is especially sensitive to OSA as measured by our proxy.

The exact mechanism underlying the relationship between OSA and task complexity in this population is still unclear. Multiple physiological processes have been implicated in general cognitive changes in uninjured adults with OSA, including effects of brief intermittent hypoxia. ${ }^{70}$ Indeed, OSA is linked to multiple neurological changes. ${ }^{32-34}$ Most relevant is evidence that OSA preferentially impacts gray matter volume of the medial frontal lobe, a region critical for cognitive control processes. ${ }^{32}$ OSA is also linked to white matter lesions and altered integrity, which are implicated in processing speed and general executive functioning. Together, these neurological changes likely impact complex tasks that rely on efficiently processing information and engaging multiple cognitive processes. Effects of these changes may be exacerbated in those with prior history of mTBI due to neurologic vulnerability, mTBI-

Table 8. Univariate and Multi-Variate Models of Subjective Cognitive Complaints

\begin{tabular}{|c|c|c|c|c|c|}
\hline \multirow[b]{2}{*}{ Outcome variable } & \multirow[b]{2}{*}{ Predictor } & \multicolumn{2}{|c|}{ Univariate model } & \multicolumn{2}{|c|}{ Multi-variate model } \\
\hline & & Estimate $(95 \%$ CI) & $p$ value & Estimate $(95 \%$ CI) & $p$ value \\
\hline \multirow[t]{6}{*}{ NSI Cognitive } & Age & $-0.010(-0.019$ to 0.000$)$ & 0.041 & $-0.017(-0.027$ to -0.006$)$ & 0.001 \\
\hline & Gender & $-0.186(-0.485$ to 0.113$)$ & 0.223 & $-0.551(-0.861$ to -0.242$)$ & 0.001 \\
\hline & Race & $-0.083(-0.279$ to 0.113$)$ & 0.405 & $-0.068(-0.253$ to 0.117$)$ & 0.469 \\
\hline & Education & $-0.229(-0.492$ to 0.033$)$ & 0.086 & $-0.189(-0.447$ to 0.069$)$ & 0.150 \\
\hline & TBI & $0.619(0.365$ to 0.874$)$ & $<0.001$ & $0.538(0.287$ to 0.789$)$ & $<0.001$ \\
\hline & STOP-BANG Score & $0.100(0.043$ to 0.157$)$ & 0.001 & $0.156(0.092$ to 0.220$)$ & $<0.001$ \\
\hline
\end{tabular}

Estimates are presented as beta values.

CI, confidence interval; NSI, Neurobehavioral Symptom Inventory; TBI, traumatic brain injury. 
related sleep disturbance, altered glymphatic clearance, or some combination of the above.

To date, only one study has examined the effects of OSA in a small sample $(n=35)$ of civilians with predominantly moderate-tosevere TBI. ${ }^{44}$ The current study extends the literature by examining the association of a common, treatable TBI comorbidity (OSA risk) on cognitive complaints often attributed to mTBI. Findings demonstrated elevated risk among those with mTBI, although etiology of this relationship remains understudied. Within the general active duty military sample, prevalence of OSA has been associated with increasing age, sex, and body mass index. ${ }^{9}$ However, specific relative risk with respect to mTBI history is still poorly understood, and additional research utilizing diagnostic polysomnography will be important moving forward.

Given the known benefits of treatment of OSA treatment on cognitive and underlying neuropathology, ${ }^{71}$ research is needed to examine treatment benefit in the chronic mTBI population. To our knowledge, a single study has examined this potential mechanism for cognitive improvement in the TBI population. Castriotta and colleagues reported treatment of post-TBI sleep disorders (collapsing across OSA, hypersomnia, narcolepsy, and periodic limb movements) was associated with decreased self-reported sleepiness with limited neuropsychological benefit. ${ }^{72}$ Given the small sample of OSA in this study $(n=13)$ with poor injury characterization and variable time elapsed since injury, the efficacy of OSA treatment remains underinvestigated.

Findings are of particular interest to the military population for which military readiness is crucial, particularly in this current era of prolonged conflicts. Untreated OSA is associated with daytime sleepiness and fatigue. These symptoms have both been identified across investigations as key aspects of decisional readiness in the military setting. ${ }^{73,74}$ In this study, complex processing speed and cognitive sequencing/multi-tasking (an executive functioning task) was uniquely associated with OSA status. These cognitive skills are crucial to active-duty SMs optimal functioning in the field. Moreover, sleep has been identified as a key element to fitness and resilience in the military. ${ }^{75}$ Finally, the sequelae of untreated OSA is associated with increased risk of workplace and motor vehicle accidents. ${ }^{12,13}$ Collectively these findings highlight the important of early identification and treatment of OSA in this population to optimize military readiness.

Strengths of this study include the large sample size recruited from a multi-center trial promoting generalizability of the results. Analyses included post-deployed participants with history of mTBI, as well as TBI-negative controls. The use of a standardized, comprehensive battery of neuropsychological tasks and perception of cognitive functioning promoted exploration of effects across cognitive domains. Finally, given the controversial nature of chronic mTBI sequelae, participants whose scores indicated invalid cognitive performance and/or symptom exaggeration on measures embedded during formal assessment were excluded to increase the validity of findings.

However, there are several limitations associated with this study. This study was specifically investigating the relationship between OSA risk and cognitive outcome. Some aspects of cardiovascular functioning, including hypertension and BMI, are included in the characterization of risk. As such, we did not duplicate their presence in the multi-variate models. This study also does not include potential mental health co-morbidities in the model. Although depression has an independent effect on cognitive functioning, depression and OSA are not independent disease processes. A growing literature demonstrates that OSA can cause or exacerbate depressive symptoms, primarily through brain changes related to vascular burden and intermittent hypoxia. ${ }^{76,77}$ To avoid circular analyses, depression was excluded from the final model. Similarly, examination of current alcohol consumption, chronic pain, and medications that may also contribute to overall functioning after injury were not included in the model.

Additionally, this study examined OSA risk as opposed to clinical diagnosis of OSA, which would require diagnostic polysomnography. The STOP-BANG is a recommended measure of OSA risk in clinical guidelines and has been used in evaluation of OSA outcomes. ${ }^{78}$ Further, our modified version of the STOPBANG may alter the determination of OSA risk. Nonetheless, significant associations were found between OSA risk and cognition. Other OSA-relevant factors (actual diagnosis, current or prior treatments, other sleep disorders, history of alcohol misuse) were not evaluated as they were not part of CENC data collection. Generalizability of findings to female military cohorts is limited due to the predominantly male sample.

Importantly, because this study utilized the STOP-BANG measure to determine sleep apnea risk, findings are interpreted within the context of obstructive sleep apnea rather than central sleep apnea (CSA). The latter is characterized not by a collapse or obstruction of the airway, but rather by a lack of drive to breathe during sleep. ${ }^{79}$ The current study is limited to investigation of OSA risk specifically, as the STOP-BANG has not demonstrated accurate CSA detection. ${ }^{80}$ However, CSA remains relevant when considering sleep-disordered breathing in individuals following TBI, as it has been linked to long-term opioid use. ${ }^{79}$ A study of hospitalized individuals with TBI demonstrated that chronic pain (for which opioids may be prescribed) is the most prevalent co-morbidity at follow-up, suggesting that opioid-induced sleep-disordered breathing resulting in CSA may be relevant in some. ${ }^{81}$ The focus on OSA risk in this study is supported by recent evidence highlighting primarily OSA, not CSA, diagnosis after TBI in both single and multicenter clinical trials. ${ }^{82,83}$ Nevertheless, future diagnostic studies of this population are needed that improve understanding of the interrelationship of sleep-disordered breathing and prevalent behavioral health co-morbidities on risk/outcome.

To conclude, this study found a unique association between OSA risk and cognition among current and former SMs. Future studies with diagnostic polysomnography are needed to determine the exact association of OSA disease severity and subsequent treatment benefits with sequelae commonly attributed to mTBI. Although polysomnography and other biometrics of sleep quality were not available in this cohort, replicating these findings with multiple sources of diagnostic data will be critical for understanding these complex relationships. To this end, our research is first step in identifying OSA as a modifiable risk factor following mTBI, and suggests that OSA serves as a potential point of intervention to improve clinical and functional outcomes after injury.

\section{Acknowledgments}

The authors would like to acknowledge the work of Deveney Ching in the preparation of this manuscript.

The views expressed in this manuscript are those of the authors and do not necessarily represent the official policy or position of the Defense Health Agency, Department of Defense (DOD), Department of Army/Navy/Air Force, Veterans Health Administration (VHA), U.S. Government, Defense and Veterans Brain Injury Center (DVBIC), or any other U.S. government agency. No official endorsement should be inferred.

Unclassified. 


\section{Funding Information}

This work was prepared under Contract W91YTZ-13-C-0015/ HT0014-19-C-0004 with VHA Central Office VA TBI Model Systems Program of Research/DHA Contracting Office (CO-NCR) HT0014 and, therefore, is defined as U.S. Government work under Title 17 U.S.C. $\$ 101$. Per Title 17 U.S.C. $\$ 105$, copyright protection is not available for any work of the U.S. Government. For more information, please contact dha.DVBICinfo@mail.mil. This material is also based upon work supported by the U.S. Army Medical Research and Material Command and from the U.S. Department of Veterans Affairs Chronic Effects of Neurotrauma Consortium under Award No. W81XWH-13-2-0095. The U.S. Army Medical Research Acquisition Activity, 820 Chandler Street, Fort Detrick MD 21702-5014 is the awarding and administering acquisition office. Further support was provided by 9Line LLC.

\section{Author Disclosure Statement}

No competing financial interests exist.

\section{References}

1. Department of Veterans Affairs and Department of Defense. (2016). VA/DOD clinical practice guideline for management of concussion/mild traumatic brain injury. Version 2.0. www.healthquality.va .gov/guidelines/Rehab/mtbi/mTBICPGFullCPG50821816.pdf (Last accessed September 18, 2019).

2. Defense and Veterans Brain Injury Center (DVBIC). (2019). DoD worldwide TBI numbers. https://dvbic.dcoe.mil/dod-worldwidenumbers-tbi (Last accessed May 19, 2020).

3. Terrio, H., Brenner, L.A., Ivins, B.J., Cho, J.M., Helmick, K., Schwab, K., Scally, K., Bretthauer, R., and Warden, D. (2009). Traumatic brain injury screening: preliminary findings in a US army brigade combat team. J. Head Trauma Rehabil. 24, 14-23.

4. Collen, J., Orr, N., Lettieri, C.J., Carter, K., and Holley, A.B. (2012). Sleep disturbances among soldiers with combat-related traumatic brain injury. Chest 142, 622-630.

5. Holster, J.L., Bryan, C.J., Heron, E.A., and Seegmiller, R.A. (2017) Traumatic brain injury, sleep, and mental health: a longitudinal study of air force personnel pre- and postdeployment to Iraq. J. Head Trauma Rehabil. 32, 25-33.

6. Walker, J.M., James, N.T., Campbell, H., Wilson, S.H., Churchill, S., and Weaver, L.K. (2016). Sleep assessments for a mild traumatic brain injury trial in a military population. Undersea Hyperb. Med. 43, 579566.

7. Wallace, D.M., Shafazand, S., Ramos, A.R., Carvalho, D.Z., Gardener, H., Lorenzo, D., and Wohlgemuth, W.K. (2011). Insomnia characteristics and clinical correlates in operation enduring freedom/operation Iraqi freedom veterans with post-traumatic stress disorder and mild traumatic brain injury: an exploratory study. Sleep Med. 12, 850-859.

8. Towns, S.J., Silva, M.A., and Belanger, H.G. (2015). Subjective sleep quality and postconcussion symptoms following mild traumatic brain injury. Brain Inj. 29, 1337-1341.

9. Mysliwiec, V., Gill, J., Lee, H., Baxter, T., Pierce, R., Barr, T.L., Krakow, B., and Roth, B.J. (2013). Sleep disorders in US military personnel: a high rate of comorbid insomnia and obstructive sleep apnea. Chest 144, 549-557.

10. Alexander, M., Ray, M.A., Hébert, J.R., Youngstedt, S.D., Zhang, H., Steck, S.E., Bogan, R.K., and Burch, J.B. (2016). The National Veteran Sleep Disorder Study: descriptive epidemiology and secular trends, 2000-2010. Sleep 39, 1399-1410.

11. Sjösten, N., Vahtera, J., Salo, P., Oksanen, T., Saaresranta, T., Virtanen, M., Pentti, J., and Kivimäki, M. (2009). Increased risk of lost workdays prior to the diagnosis of sleep apnea. Chest 136, 130-136.

12. Young, T., Blustein, J., Finn, L., and Palta, M. (1997). Sleepdisordered breathing and motor vehicle accidents in a populationbased sample of employed adults. Sleep 20, 608-613.

13. Sassani, A., Findley, L.J., Kryger, M., Goldlust, E., George, C., and Davidson, T.M. (2004). Reducing motor-vehicle collisions, costs, and fatalities by treating obstructive sleep apnea syndrome. Sleep 27, 453-458.

14. Dash, M.B., Douglas., C.L., Vyazovskiy, V.V., Cirelli, C., and Tononi, G. (2009). Long-term homeostasis of extracellular glutamate in the rat cerebral cortex across sleep and waking states. J. Neurosci. 29, 620-629.

15. Longordo, F., Kopp, C., and Lüthi A. (2009). Consequences of sleep deprivation on neurotransmitter receptor expression and function. Eur. J. Neurosci. 29, 1810-1819.

16. McDermott, C.M., LaHoste, G.J., Chen, C., Musto, A., Bazan, N.G., and Magee, J.C. (2003). Sleep deprivation causes behavioral, synaptic, and membrane excitability alterations in hippocampal neurons. J. Neurosci. 23, 9687-9695.

17. Walker, M.P. (2009). The role of sleep in cognition and emotion. Ann. N. Y. Acad. Sci. 1156, 168-197.

18. Zunzunegui, C., Gao, B., Cam, E., Hodor, A., and Bassetti, C.L. (2011). Sleep disturbance impairs stroke recovery in the rat. Sleep 34, 1261-1269.

19. Asken, B.M., Sullan, M.J., Snyder, A.R., Houck, Z.M., Bryant, V.E., Hizel, L.P., McLaren, M.E., Dede, D.E., Jaffe, M.S., DeKosky, S.T., and Bauer, R.M. (2016). Factors influencing clinical correlates of chronic traumatic encephalopathy (CTE): a review. Neuropsychol. Rev. 26, 340-363.

20. Sun, B.L., Wang, L.H., Yang, T., Sun, J.Y., Mao, L.L., Tang, M.F., Yuan, H., Colvin, R.A., and Tang, X.Y. (2018). Lymphatic drainage system of the brain: a novel target for intervention of neurological diseases. Prog. Neurobiol. 163, 118-143.

21. Xie, L., Kang, H., Xu, Q., Chen, M.J., Liao, Y., Thiyagarajan, M., O’Donnell, J., Christensen, D.J., Nicholson, C., Iliff, J.J., Takano, T., Deane, R., and Nefergaard, M. (2013). Sleep drives metabolite clearnace from the adult brain. Science 342, 373-377.

22. Mendelsohn, A.R. and Larrick, J.W. (2013). Sleep facilitates clearance of metabolites from the brain: glympathic function in aging and neurodegenerative diseases. Rejuvenation Res. 16, 518-523.

23. Fultz, N., Bonmassar, G., Setsompop, K., Stickgold, R.A., Rosen, B.R., Polimeni, J.R., and Lewis, L.D. (2019). Coupled electrophysiological, hemodynamic, and cerebrospinal fluid oscillations in human sleep. Science 366, 628-631.

24. Bacyinski, A., Xu, M., Wang, W., and Hu, J. (2017). The paravascular pathway for brain waste clearance: current understanding, significance and controversy. Front. Neuroanat. 11, 101.

25. Boespflug, E.L., and Iliff, J.J. (2018). The emerging relationship between interstitial fluid-cerebrospinal fluid exchange, amyloid- $\beta$, and sleep. Biol. Psychiatry 83, 328-336.

26. Kim, H., Yun, C.H., Thomas, R.J., Lee, S.H., Seo, H.S., Cho, E.R., Lee, S.K., Yoon, D.W., Suh, S., and Shin, C. (2013). Obstructive sleep apnea as a risk factor for cerebral white matter change in a middle-aged and older general population. Sleep 36, 709-715B.

27. Bliwise, D.L. (2013). Alzheimer's disease, sleep apnea, and positive pressure therapy. Curr. Treat. Options Neurol. 15, 669-676.

28. Beebe, D.W., Groesz, L., Wells, C., Nichols, A., and McGee, K. (2003). The neuropsychological effects of obstructive sleep apnea: a meta-analysis of norm-referenced and case-controlled data. Sleep 26, 298-307.

29. Bucks, R.S., Olaithe, M., and Eastwood, P. (2013). Neurocognitive function in obstructive sleep apnea: a meta-review. Respirology 18, 61-70.

30. Olaithe, M., Bucks, R.S., Hillman, D.R., and Eastwood, P.R. (2018) Cognitive deficits in obstructive sleep apnea: insights from a metareview and comparison with deficits observed in COPD, insomnia, and sleep deprivation. Sleep Med. Rev. 38, 39-49.

31. Wallace, A. and Bucks, R.S. (2013). Memory and obstructive sleep apnea: a meta-analysis. Sleep 36, 203-220.

32. Shi, Y., Lizhou, C., Chen, T., Li, L., Dai, K., Lui, S., Huang, X., Sweeney, J.A., and Gong, Q. (2017). A meta-analysis of voxel-based brain morphometry studies in obstructive sleep apnea. Sci. Rep. 7, 10095.

33. Ho, B.L., Tseng, P.T., Lai, C.L. Wu, M.N., Tsai, M.J., Hsieh, C.F., Chen, T.Y., and Hsu, C.Y. (2018). Obstructive sleep apnea and cerebral white matter change: a systematic review and meta-analysis. J. Neurol. 265, 1643-1653.

34. Zhang, Q., Wang, D., Qin, W., Li, Q., Chen, B., Zhang, Y., and Yu, C. (2013). Altered resting-state brain activity in obstructive sleep apnea. Sleep 36, 651-659B. 
35. Innes, C.R., Kelly, P.T., Hlavac, M., Melzer, T.R., and Jones, R.D. (2015). Decreased regional cerebral perfusion in moderate-severe obstructive sleep apnoea during wakefulness. Sleep 38, 699-0706.

36. Pan, Y.Y., Deng, Y., Xu, X., Liu, Y.P., and Lui, H.G. (2015). Effects of continuous positive airway pressure on cognitive deficits in middleaged patients with obstructive sleep apnea syndrome: a meta-analysis of randomized controlled trails. Chin. Med. J. 128, 2365-2373.

37. Castronovo, V., Scifo, P., Castellano, A., Aloia, M.S., Iadanza, A., Marelli, S., Cappa, S.F., Strambi, L.F., and Falini, A. (2014). White matter integrity in obstructive sleep apnea before and after treatment. Sleep 37, 1465-1475.

38. Mathias, J.L. and Wheaton, P. (2007). Changes in attention and information-processing speed following severe traumatic brain injury: a meta-analytic review. Neuropsychology 21, 212-223.

39. Gordon, W.A., Haddad, L., Brown, M., Hibbard, M.R., and Sliwinski, M. (2000). The sensitivity and specificity of self-reported symptoms in individuals with traumatic brain injury. Brain Inj. 14, 21-33.

40. Belanger, H.G., Kretzmer, T., Vanderploeg, R.D., and French, L.M. (2010). Symptom complaints following combat-related traumatic brain injury: relationship to traumatic brain injury severity and posttraumatic stress disorder. J. Int. Neuropsychol. Soc. 16, 194-199.

41. Belanger, H.G., Curtiss, G., Demery, J.A., Lebowitz, B.K., and Vanderploeg, R.D. (2005). Factors moderating neuropsychological outcomes following mild traumatic brain injury: a meta-analysis. J. Int Neuropsychol. Soc. 11, 215-227.

42. Karr, J.E., Areshenkoff, C.N., and Garcia-Barrera, M.A. (2014). The neuropsychological outcomes of concussion: a systematic review of meta-analyses on the cognitive sequelae of mild traumatic brain injury. Neuropsychology 28, 321-336.

43. Rohling, M.L., Binder, L.M., Demakis, G.J., Larrabee, G.J., Ploetz, D.M., and Langhinrichsen-Rohling, J. (2011). A meta-analysis of neuropsychological outcome after mild traumatic brain injury: reanalyses and reconsiderations of Binder et al. (1997), Frencham et al. (2005), and Pertab et al. (2009). Clin. Neuropychol. 25, 608-623.

44. Wilde, M.C., Castriotta, R.J., Lai, J.M., Atanasov, S., Masel, B.E., and Kuna, S.T. (2007). Cognitive impairment in patients with traumatic brain injury and obstructive sleep apnea. Arch. Phys. Med. Rehabil. 88, 1284-1288.

45. Vogt, D., Smith, B.N., King, L.A., King, D.W., Knight, J., and Vasterling, J.J. (2013). Deployment risk and resilience inventory-2 (DRRI-2): an updated tool for assessing psychosocial risk and resilience factors among service members and veterans. J. Trauma Stress 26, 710-117.

46. Corrigan, J.D. and Bogner, J. (2007). Initial reliability and validity of the Ohio State University TBI Identification Method. J. Head Trauma Rehabil. 22, 318-329.

47. Walker, W.C., Cifu, D.X., Hudak, A.M., Goldberg, G., Kunz, R.D., and Sima, A.P. (2015). Structured interview for mild traumatic brain injury after military blast: inter-rater agreement and development of diagnostic algorithm. J. Neurotrauma 32, 464-473.

48. Chung, F., Yegneswaran, B., Liao, P., Chung, S.A., Vairavanathan, S., Islam, S., Khajehdehi, A., and Shapiro, C.M. (2008). STOP questionnaire: a tool to screen patients for obstructive sleep apnea. Anesthesiology 108, 812-821.

49. Buysse, D.J., Reynolds III, C.F., Monk, T.H., Berman, S.R., and Kupfer, D.J. (1989). The Pittsburgh Sleep Quality Index: a new instrument for psychiatric practice and research. Psychiatry Res. 28, $193-213$

50. U.S. Centers for Disease Control and Prevention. (1998). Behavioral Risk Factor Surveillance System User's Guide. Centers for Disease Control and Prevention: Atlanta, GA.

51. Jacobs, M.L. and Donders, J. (2007). Criterion validity of the California Verbal Learning Test-Second Edition (CVLT-II) after traumatic brain injury. Arch. Clin. Neuropsychol. 22, 143-149.

52. DeJong, J. and Donders, J. (2010). Cluster subtypes on the California Verbal Learning Test-Second Edition (CVLT-II) in a traumatic brain injury sample. J. Clin. Exp. Neuropsychol. 32, 953-960.

53. Field, M., Collins, M.W., Lovell, M.R., and Maroon, J. (2003). Does age play a role in recovery from sports-related concussion? A comparison of high school and collegiate athletes. J. Pediatr. 142, 546553.

54. McCauley, S.R, Wilde, E.A, Barnes, A., Hanten, G., Hunter, J.V., Levin, H.S., and Smith, D.H. (2014). Patterns of early emotional and neuropsychological sequelae after mild traumatic brain injury. J. Neurotrauma 31, 914-925.
55. Rabinowitz, A.R., Li, X, McCauley, S.R., Wilde, E.A., Barnes, A., Hanten, G., Mendez, D., McCarthy, J.J., and Levin, H.S. (2015). Prevalence and predictors of poor recovery from mild traumatic brain injury. J. Neurotrauma 32, 1488-1496.

56. Lange, R.T., Iverson, G.L., Zakrzewski, M.J., Ethel-King, P.E., and Franzen, M.D. (2005). Interpreting the trail making test following traumatic brain injury: comparison of traditional time scores and derived indices. J. Clin. Exp. Neuropsychol. 27, 897-906.

57. Dreer, L.E., DeVivo, M.J., Novack, T.A., Krzywanski, S., and Marson, D.C. (2008). Cognitive predictors of medical decisionmaking capacity in traumatic brain injury. Rehabil. Psychol. 53, 486-497.

58. Carlozzi, N.E., Kirsch, N.L., Kisala, P.A., and Tulsky, D.S. (2015). An examination of the Wechsler Adult Intelligence Scales, Fourth Edition (WAIS-IV) in individuals with complicated mild, moderate and severe traumatic brain injury (TBI). Clin. Neuropsychol. 29, 21-37.

59. Tulsky, D.S., Carlozzi, N.E., Holdnack, J., Heaton, R.K., Wong, A., Goldsmith, A., Heinemann, A.W. (2017). Using the NIH Toolbox Cognition Battery (NIHTB-CB) in individuals with traumatic brain injury. Rehabil. Psychol. 62, 413-424.

60. Meterko, M., Baker, E., Stolzmann, K.L., Hendricks, A.M., Cicerone, K.D., and Lew, H.L. (2012). Psychometric assessment of the Neurobehavioral Symptom Inventroy-22: the structure of persistent postconcussive symptoms following deployment-related mild traumatic brain injury among veterans. J. Head Trauma Rehabil. 27, 55-62.

61. Delis, D.C., Kramer, J.H., Kaplan, E., and Ober, B.A. (2000). California Verbal Learning Test-Second Edition (CVLT-II). The Psychological Corporation: San Antonio, TX

62. Benedict, R.H., Schretlen, D., Groninger, L., Dobraski, M., and Shpritz, B. (1996). Revision of the Brief Visuospatial Memory Test: studies of normal performance, reliability, and validity. Psychol. Assess. 8, 145 .

63. Reitan, R.M., and Wolfson, D. (1985). The Halstead-Reitan Neuropsychological Test Battery: Therapy and Clinical Interpretation. Neuropsychological Press: Tuscon, AZ.

64. Wechsler, D. (2008). Wechsler Adult Intelligence Scale-Fourth Edition (WAIS-IV). Pearson: San Antonio, TX, pp. 498.

65. Weintraub, S., Dikmen, S.S., Heaton, R.K., Tulsky, D.S., Zelazo, P.D., Bauer, P.J., Carlozzi, N.E., Slotkin, J., Blitz, D., Wallner-Allen, K., Fox, N.A., Beaumont, J.L., Mungas, D., Nowinski, C.J., Richler, J., Deocampo, J.A., Anderson, J.E., Manly, J.J., Borosh, B., Havlik, R., Conway, K., Edwards, E., Freund, L., King, J.W., Moy, C., Witt, E., and Gershon, R.C. (2013). Cognition assessment using the NIH Toolbox. Neurology 80(11 Suppl 3), S54-S64.

66. Cicerone, K.D. and Kalmar, K. (1995). Persistent postconcussion syndrome: the structure of subjective complaints after mild traumatic brain injury. J. Head Trauma Rehabil. 10, 1-17.

67. IBM SPSS Statistics for Windows, Version 25. IBM Corp.: Armonk, N.Y.

68. Walker, J.M., James, N.T., Campbell, H., Wilson, S.H., Churchill, S., and Weaver, L.K. (2016). Sleep assessments for a mild traumatic brain injury trial in a military population. Undersea Hyperb. Med. 43, 549566.

69. Collen, J., Orr, N., Letteri, C.J., Carter, K., and Holley, A.B. (2012). Sleep disturbances among soldiers with combat-related traumatic brain injury. Chest 142, 622-630.

70. Gale, S.D. and Hopkins, R.O. (2004). Effects of hypoxia on the brain: neuroimaging and neuropsychological findings following carbon monoxide poisoning and obstructive sleep apnea. J. International Neuropsychol. Soc. 10, 60-71.

71. Castronovo, V., Scifo, P., Castellano, A., Aloia, M.S., Iadanza, A., Marelli, S., Cappa, S.F., Strambi, L.F., and Falini, A. (2014). White matter integrity in obstructive sleep apnea before and after treatment. Sleep 37, 1465-1475.

72. Castriotta, R.J., Atanasov, S., Wilde, M.C., Masel, B.E., Lai, J.M., and Kuna, S.T. (2009). Treatment of sleep disorders after traumatic brain injury. J. Clin. Sleep Med. 5, 137-144.

73. Miller, N.L., Shattuck, L.G., and Matsangas, P. (2011). Sleep and fatigue issues in continuous operations: a survey of U.S. Army officers. Behav. Sleep Med. 9, 53-65.

74. Troxel, W.M., Shih, R.A., Pedersen, E.R., Geyer, L., Fisher, M.P., Griffin, B.A., Haas, A.C., Kurz, J., and Steinberg, P.S. (2015). Sleep in the military: promoting healthy sleep among U.S. servicemembers. Rand Health Q. 5, 19. 
75. Lentino, C.V., Purvis, D.L., Murphy, K.J., and Deuster, P.A. (2013). Sleep as a component of the performance triad: the importance of sleep in a military population. U.S. Army Med. Dep. J. 98-108.

76. Kerner, N.A. and Roose, S.P. (2016). Obstructive sleep apnea is linked to depression and cognitive impairment: evidence and potential mechanisms. Am. J. Geriatr. Psychiatry 24, 496-508.

77. Chirinos, D.A., Gurubhagavatula, I., Broderick, P., Chirinos, J.A., Teff, K., Wadden, T., Maislin, G., Saif, H., Chittams, J., Cassidy, C. and Hanlon, A.L. (2017). Depressive symptoms in patients with obstructive sleep apnea: biological mechanistic pathways. J. Behav. Med. 40, 955-963.

78. Chung, F., Abdullah, H.R., and Liao, P. (2016). STOP-Bang Questionnaire: a practical approach to screen for obstructive sleep apnea. Chest 149, 631-638.

79. Eckert, D.J., Jordan, A.S., Merchia, P., \& Malhotra, A. (2007). Central sleep apnea: pathophysiology and treatment. Chest 131, 595-607.

80. Reuter, H., Herkenrath, S., Treml, M., Halbach, M., Steven, D., Frank, K., Castrogiovanni, A., Kietzmann, I., Baldus, S., and Randerath, W. (2018). Sleep-disordered breathing in patients with cardiovascular diseases cannot be detected by ESS, STOP-BANG, and Berlin questionnaires. Clin. Res. Cardiol. 107, 1071-1078.

81. Hammond, F. M., Corrigan, J. D., Ketchum, J. M., Malec, J. F., Dams-O’Connor, K., Hart, T., Novack, T., Bogner, J., Dahdah, M., and Whiteneck, G. G. (2019). Prevalence of medical and psychi- atric comorbidities following traumatic brain injury. J. Head Trauma Rehab. 34, E1-E10.

82. Nakase-Richardson, R., Schwartz, D., Ketchum, J., Drasher-Phillips, L., Dahdah, M., Monden, K., Bell, K., Hoffman, J., Whyte, J., Bogner, J., Calero, K., and Magalang, U. (2020). Comparison of diagnostic sleep studies in moderate to severe traumatic brain injury neurorehabilitation admissions. Chest 2020 May 6; E-pub ahead of print.

83. Nakase-Richardson, R., Schwartz, D.J., Drasher-Phillips, L., Ketchum, J.M., Calero, K., Dahdah, M.N., Monden, K.R., Bell, K., Magalang, U., Hoffman, J., Whyte, J., Bogner, J., and Zeitzer, J. (2020). Comparative effectiveness of sleep apnea screening instruments during inpatient rehabilitation following moderate to severe TBI. Arch. Phys. Med. Rehabil. 101, 283-296.

Address correspondence to: Amanda Garcia, PhD

Defense and Veterans Brain Injury Center

James A. Haley VA Hospital 13000 Bruce B Downs Boulevard

Tampa, FL 33612

USA

E-mail: amanda.garcia3@va.gov 